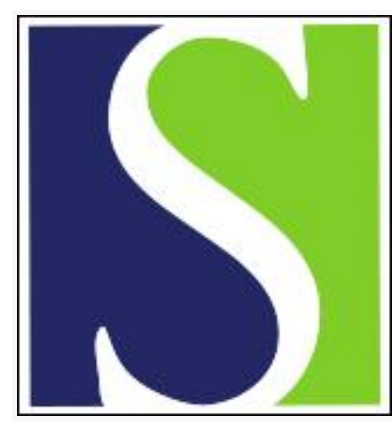

Scand J Work Environ Health 1989;15(5):360-363

https://doi.org/10.5271/sjweh.1848

Issue date: Oct 1989

Association of childhood cancer with residential traffic density. by Savitz DA, Feingold L

Affiliation: Department of Epidemiology, School of Public Health, University of North Carolina, Chapel Hill 27599.

This article in PubMed: www.ncbi.nlm.nih.gov/pubmed/2477895 


\title{
Association of childhood cancer with residential traffic density
}

\author{
by David A Savitz, $\mathrm{PhD},{ }^{1}$ Lisa Feingold, $\mathrm{MSPH},{ }^{1,2}$
}

\begin{abstract}
SA VITZ DA, FEINGOLD L. Association of childhood cancer with residential traffic density. Scand $J$ Work Environ Health 1989;15:360 - 363. Data from a recently completed case-referent study of childhood cancer were used to explore a possible role of environmental exposures from traffic exhaust. The street addresses of 328 cancer patients and 262 population-based referents were used to assign traffic density (vehicles per day) as a marker of potential exposure to motor vehicle exhaust. An odds ratio of 1.7 [95\% confidence interval $(95 \% \mathrm{Cl}) 1.0-2.8$ ] was found for the total number of childhood cancers and $2.1(95 \%$ CI $1.1-4.0)$ for leukemias in a contrast of high and low traffic density addresses ( $\geq 500$ versus $<500$ vehicles per day). Stronger associations were found with a traffic density cutoff score of $\geq 10000$ vehicles per day, with imprecise odds ratios of $3.1(95 \% \mathrm{CI} 1.2-8.0)$ and $4.7(95 \% \mathrm{CI} 1.6 \cdots-13.5)$ for the total number of cancers and leukemias, respectively. Adjustment for suspected risk factors for childhood cancer did not substantially change these results. Though the results are inconclusive, the identified association warrants further evaluation.
\end{abstract}

Key terms: air pollution, benzene, brain cancer, leukemia, motor vehicle exhaust.

Environmental influences on the development of childhood cancer have been of interest for some time $(1-3)$, but epidemiologists have had very little success in identifying exogenous etiologic agents for these diseases (4). Given that the etiology of childhood cancer is largely unexplained and the study of environmental agents has been limited, there is a need for further exploratory evaluations of exposures not previously considered.

An examination of risk factors for the most prevalent childhood cancers (leukemia, brain cancer, and lymphomas) in adults would also provide few etiologic clues. One of the few established causes of adult leukemia is benzene (5), whereas other solvents are suspected of causing leukemia (6) and possibly brain cancer (7). Evidence that benzene in gasoline produces detectable concentrations in the ambient air as high as 10-20 $\mu \mathrm{g} / \mathrm{m}^{3}$ in urban areas $(8,9)$ makes this potential consequence of traffic density worthy of evaluation, along with the contribution of motor vehicles to environmental lead and hydrocarbon levels. Data from a study designed to examine electromagnetic fields and childhood cancer were used to assess whether any of these exposures might be related to childhood cancer incidence in Denver, Colorado.

\footnotetext{
1 Department of Epidemiology, School of Public Health, University of North Carolina, Chapel Hill, North Carolina, United States.

2 Currently at the Department of Community Health, Brown University School of Medicine, Providence, Rhode Island, United States.
}

Reprint requests to: Dr DA Savitz, Department of Epidemiology, Campus Box 7400, School of Public Health, University of North Carolina, Chapel Hill, NC 27599, USA.

\section{Materials and methods}

The details of the study methods have been provided elsewhere (10) and are therefore outlined only briefly in this report. The eligible cases consisted of all incident childhood cancers (age of child $0-14$ years) diagnosed between 1 January 1976 and 31 December 1983 among residents of the 1970 Standard Metropolitan Statistical Area (Adams, Arapahoe, Boulder, Denver, and Jefferson counties) of Denver, Colorado. The Colorado Central Cancer Register was complete for the period 1979-1982, and area hospitals provided access to additional cases, which allowed comprehensive ascertainment throughout the study period. Of the cases, $95.2 \%$ were histologically confirmed, and an additional $3.1 \%$ were confirmed by direct visualization or radiography (11).

The referents were selected by random digit dialing, matched to cases by the age (plus or minus 3 years), sex, and telephone exchange area of the patient. Although referents were sought for each case, the inclusion of a given case or referent in the analysis was not affected by our ability to produce a matched pair. The intent was to produce a group balanced on the matching criteria, and the data were analyzed through stratified rather than matched analysis (12).

In order to ensure that the referents occupied their homes in the patient's telephone exchange area at the time of the case's diagnosis, only potential referents who had stayed in their home from the time of the case's diagnosis to the time of the interview (when they were determined to reside in the correct telephone exchange area) were eligible. Although it would have been preferable to include potential referents who previously resided in the area but subsequently moved, there was no mechanism for identifying and contacting such families in their new locations. Thus referents were restricted to have been occupants of their 
homes at the time the case was diagnosed (whereas cases were not so restricted); therefore more residentially stable referents than cases were produced (10).

In this analysis, the residence occupied at the time of the case's diagnosis (or at the referent's age when the matched case was diagnosed) was characterized with respect to traffic density. The location of each reported address was identified on a detailed street map of the Denver Standard Metropolitan Statistical Area. On the basis of the precise location, the approximate location of the homes was identified on traffic density maps provided by the Denver Division of Highway Planning and Research, and the specific segment of the street to which the density figures applied was carefully noted. On the basis of the maps and lists of the streets and traffic volumes, the home was assigned a traffic density score of $<500$ vehicles per day or the recorded number of vehicles per day (ranging from 500 to over 100000 per day).

Data on potential confounders were collected principally through an interview with the parent (mother preferred) regarding numerous potential risk factors such as family demography, cancer history, exposure to $\mathrm{X}$ rays and medications during pregnancy, parents' occupational history, and mother's and child's illnesses. Wire configuration codes were obtained as a marker of long-term magnetic field exposure (10). On the basis of associations with childhood cancer (either risk factors or artifacts of the study design), the following variables were examined in detail: sex, age, year of diagnosis, single-family versus multiple occupancy residence, residence in or out of Denver at birth, residential mobility from birth to diagnosis, mother's age, father's education, per capita income, mother's smoking during pregnancy, and wire code at the time of diagnosis. (Note that the markers of residential stability would address the possible bias from the restriction of referents based on long-term occupancy of their homes.)

Odds ratios and $95 \%$ confidence intervals were calculated with test-based methods (13). Stratified analyses produced Mantel-Haenszel adjusted odds ratios and confidence intervals (14). Finally, unconditional logistic regression analysis was used to control for multiple potential confounders (15).

\section{Results}

A total of 356 eligible cases (103 leukemias, 83 acute lymphocytic leukemias, 67 brain cancers, 35 lymphomas, 32 soft-tissue tumors, and 119 others) and 278 potential referents were identified through randomdigit dialing. For the eligible cases, traffic densities were obtained for $328(92 \%)$, with a similar response across diagnostic groups. The response for referents was $94 \%$ on the basis of 262 completed residences, which is combined with the estimated $79 \%$ response in telephone screening (10) to produce an overall $75 \%$ response. Nonrespondent cases were more likely to have been diagnosed earlier and be Hispanic or Black; no information was available concerning nonrespondent referents.

The crude results relating traffic density to childhood cancer incidence are provided in table 1 . The association for total childhood cancers [odds ratio (OR) 1.7] was slightly greater for leukemia (OR 2.1) though not acute lymphocytic leukemia (OR 1.6). Similar effect estimates (OR 1.6-1.8) were obtained for brain cancer and other cancers, with a diminished association for soft-tissue tumors and the absence of an association for lymphomas. Because the referent selection procedures failed to provide a referent for each case, the possibility of bias due to incomplete coverage was examined in a matched analysis. Though the precision was greatly reduced, the matched odds ratio for all childhood cancers was 2.0 (based on 36 discordant pairs), similar to the results of the unmatched analysis.

The more highly exposed group ( $\geq 500$ vehicles/d) was subdivided for an examination of the possible exposure-response gradients (table 2), although small numbers limited this analysis to the total number of cancers and leukemias. A cutoff score of 5000 vehicles/d yielded odds ratios of 1.8 [95\% confidence interval $(95 \% \mathrm{CI}$ ) $0.9-3.3$ ] for the total number of cancers and $2.7(95 \% \mathrm{Cl} \mathrm{1.3-5.9)}$ for leukemias in the highest exposure group. An even more pronounced gradient was found with a higher cutoff score of 10000 vehicles/d, with odds ratios of $3.1(95 \%$ CI 1.2-8.0) for total cancers and $4.7(95 \%$ CI 1.6-13.5) for leukemias in the highest exposure group.

As noted earlier, data on potential confounders were obtained in an interview with the subjects' parents, with adjusted results restricted to the subset of interviewed cases and referents ( $71 \%$ of eligible cases and $80 \%$ of identified referents). This restriction alone (in the absence of any confounding) raised the odds ratios slightly, especially for leukemia (OR 2.3) and brain cancer (OR 2.6). Adjustment for sex, age, year of diag-

Table 1. Odds ratios (OR) and $95 \%$ confidence intervals (95\% Cl) for traffic density and childhood cancer.

\begin{tabular}{|c|c|c|c|c|}
\hline \multirow{2}{*}{ Grolip } & \multicolumn{2}{|c|}{ Vehicles/day } & \multirow{2}{*}{ OR } & \multirow{2}{*}{$95 \% \mathrm{Cl}$} \\
\hline & $<500$ & $\geq 500$ & & \\
\hline Reference & 238 & 24 & . & . \\
\hline \multicolumn{5}{|l|}{ Case } \\
\hline Leukemias & 81 & 17 & 2.1 & $1.1-4.0$ \\
\hline $\begin{array}{l}\text { Acute lymphocytic } \\
\text { leukemia }\end{array}$ & 68 & 11 & 1.6 & $0.8-3.4$ \\
\hline Lymphoma & 29 & 2 & 0.7 & $0.2-3.0$ \\
\hline Brain & 52 & 9 & 1.7 & $0.8-3.9$ \\
\hline Soft tissue & 28 & 4 & 1.4 & $0.5-4.4$ \\
\hline Other & 90 & 16 & 1.8 & $0.9-3.5$ \\
\hline Total & 280 & 48 & 1.7 & $1.0-2.8$ \\
\hline
\end{tabular}


Table 2. Dose-response gradient for traffic density and total childhood cancer and leukemias: odds ratios (OR) and $95 \%$ confidence intervals $(95 \% \mathrm{Cl})$.

\begin{tabular}{|c|c|c|c|c|c|c|c|}
\hline \multirow{2}{*}{ Vehicles per day } & \multirow{2}{*}{$\begin{array}{l}\text { Referents } \\
\text { (N) }\end{array}$} & \multicolumn{3}{|c|}{ Total cases } & \multicolumn{3}{|c|}{ Leukemias } \\
\hline & & $N$ & OR & $95 \% \mathrm{Cl}$ & $N$ & OR & $95 \% \mathrm{Cl}$ \\
\hline $\begin{array}{l}<500 \\
500-4999 \\
\geq 5000\end{array}$ & $\begin{array}{r}238 \\
10 \\
14\end{array}$ & $\begin{array}{r}280 \\
19 \\
29\end{array}$ & $\begin{array}{l}1.0 \\
1.6 \\
1.8\end{array}$ & $\begin{array}{l}0.7-3.5 \\
0.9-3.3\end{array}$ & $\begin{array}{r}81 \\
4 \\
13\end{array}$ & $\begin{array}{l}1.0 \\
1.2 \\
2.7\end{array}$ & $\begin{array}{l}0.4-3.9 \\
1.3-5.9\end{array}$ \\
\hline $\begin{array}{l}500-9999 \\
\geq 10000\end{array}$ & $\begin{array}{r}19 \\
5\end{array}$ & $\begin{array}{l}30 \\
18\end{array}$ & $\begin{array}{l}1.3 \\
3.1\end{array}$ & $\begin{array}{l}0.7-2.4 \\
1.2-8.0\end{array}$ & $\begin{array}{l}9 \\
8\end{array}$ & $\begin{array}{l}1.4 \\
4.7\end{array}$ & $\begin{array}{l}0.6-3.2 \\
1.6-13.5\end{array}$ \\
\hline
\end{tabular}

Table 3. Sex-and age-specific odds ratios (OR) and $95 \%$ confidence intervals (95\% $\mathrm{Cl}$ ) for traffic density and total childhood cancer, leukemias, and brain cancers for selected stratification factors.

\begin{tabular}{|c|c|c|c|c|c|c|c|c|c|c|}
\hline \multirow{3}{*}{ Sex } & \multirow{2}{*}{$\begin{array}{c}\text { Referents } \\
\text { (exposed/ } \\
\text { unexposed) }\end{array}$} & \multicolumn{3}{|c|}{ Total cancers } & \multicolumn{3}{|c|}{ Leukemias } & \multicolumn{3}{|c|}{ Brain tumors } \\
\hline & & \multicolumn{2}{|c|}{$\begin{array}{c}\text { Exposed/ } \\
\text { unexposed }\end{array}$} & \multirow[t]{2}{*}{$95 \% \mathrm{Cl}$} & \multicolumn{2}{|c|}{$\begin{array}{l}\text { Exposed/ } \\
\text { unexposed }\end{array}$} & \multirow[t]{2}{*}{$95 \% \mathrm{Cl}$} & \multicolumn{2}{|c|}{$\begin{array}{l}\text { Exposed/ } \\
\text { unexposed }\end{array}$} & \multirow[t]{2}{*}{$95 \% \mathrm{Cl}$} \\
\hline & & & & & & & & & & \\
\hline $\begin{array}{l}\text { Male } \\
\text { Female }\end{array}$ & $\begin{array}{c}10 / 115 \\
4 / 79\end{array}$ & $\begin{array}{l}15 / 127 \\
13 / 86\end{array}$ & $\begin{array}{l}1.4 \\
3.0\end{array}$ & $\begin{array}{l}0.6-3.1 \\
1.0-9.2\end{array}$ & $\begin{array}{l}7 / 36 \\
3 / 24\end{array}$ & $\begin{array}{l}2.2 \\
2.5\end{array}$ & $\begin{array}{l}0.8-6.2 \\
0.5-11.4\end{array}$ & $\begin{array}{l}3 / 22 \\
4 / 15\end{array}$ & $\begin{array}{l}1.6 \\
5.3\end{array}$ & $\begin{array}{l}0.4-6.1 \\
1.3-20.9\end{array}$ \\
\hline \multicolumn{11}{|l|}{ Age (years) } \\
\hline $\begin{array}{l}0-4 \\
5-14\end{array}$ & $\begin{array}{l}5 / 84 \\
9 / 108\end{array}$ & $\begin{array}{l}19 / 91 \\
9 / 120\end{array}$ & $\begin{array}{l}3.5 \\
0.9\end{array}$ & $\begin{array}{l}1.3-9.4 \\
0.3-2.4\end{array}$ & $\begin{array}{l}9 / 27 \\
1 / 33\end{array}$ & $\begin{array}{l}5.6 \\
0.4\end{array}$ & $\begin{array}{l}1.9-16.7 \\
0.1-2.8\end{array}$ & $\begin{array}{l}4 / 13 \\
3 / 24\end{array}$ & $\begin{array}{l}5.2 \\
1.5\end{array}$ & $\begin{array}{l}1.4-19.6 \\
0.4-5.9\end{array}$ \\
\hline \multicolumn{11}{|c|}{ Residential stability } \\
\hline $\begin{array}{l}\text { Stable } \\
\text { Moved }\end{array}$ & $\begin{array}{c}2 / 77 \\
11 / 108\end{array}$ & $\begin{array}{l}12 / 71 \\
15 / 127\end{array}$ & $\begin{array}{l}6.5 \\
1.2\end{array}$ & $\begin{array}{l}1.7-25.4 \\
0.5-2.6\end{array}$ & $\begin{array}{l}3 / 18 \\
6 / 36\end{array}$ & $\begin{array}{l}6.4 \\
1.6\end{array}$ & $\begin{array}{l}1.2-34.0 \\
0.6-4.7\end{array}$ & $\begin{array}{l}4 / 14 \\
3 / 21\end{array}$ & $\begin{array}{r}11.0 \\
1.4\end{array}$ & $\begin{array}{l}2.4-49.8 \\
0.4-5.5\end{array}$ \\
\hline \multicolumn{11}{|c|}{ Year of diagnosis } \\
\hline $\begin{array}{l}\text { Before } 1980 \\
1980 \text { or later }\end{array}$ & $\begin{array}{l}6 / 94 \\
8 / 100\end{array}$ & $\begin{array}{l}11 / 91 \\
17 / 122\end{array}$ & $\begin{array}{l}1.9 \\
1.7\end{array}$ & $\begin{array}{l}0.7-5.3 \\
0.7-4.2\end{array}$ & $\begin{array}{l}4 / 25 \\
6 / 35\end{array}$ & $\begin{array}{l}2.5 \\
2.1\end{array}$ & $\begin{array}{l}0.7-9.3 \\
0.7-6.5\end{array}$ & $\begin{array}{l}2 / 18 \\
5 / 19\end{array}$ & $\begin{array}{l}1.7 \\
3.3\end{array}$ & $\begin{array}{l}0.3-9.2 \\
1.0-10.6\end{array}$ \\
\hline
\end{tabular}

nosis, type of residence (single family, other), location at birth (Denver, other), mother's age, father's education, per capita income, and wire configuration code at diagnosis had little effect except for a tendency of residence type to diminish the odds ratios and mother's age and mother's smoking to elevate the odds ratios. The logistic regression analysis for the total number of cancers, leukemias, and brain tumors with these three variables in the model (plus wire code for leukemia) produced adjusted odds ratios of 1.7 for the total number of cancers $(95 \% \mathrm{CI} 0.8-3.6), 1.9$ for leukemias $(95 \% \mathrm{Cl} 0.7-5.1)$, and 2.0 for brain tumors (95\% CI 0.7-6.1). Overall, these results provide evidence against substantial confounding by the measured potential risk factors.

The sex-and age-specific results for the total number of cancers, leukemias, and brain tumors are presented in table 3 . The imprecision within strata is apparent, but there is a suggestion of enhanced associations for the females (especially for brain tumors) and a consistently stronger effect for the 0 - to 4 -yearold than for the 5- to 14-year-old children. Though only crude results are reported in table 3 , logistic regression with adjustment for residence type, mother's age, and mother's smoking did not materially change the effect estimates, although the precision was further reduced.

\section{Discussion}

These results indicate an association between traffic density near the home occupied at the time of diagnosis and childhood cancer which was not accounted for by potential confounders. The odds ratios were on the order of 1.6-2.0 for all cancers except lymphomas and soft-tissue tumors. Stronger but less precise associations were observed for females, younger children (age $0-4$ years), and residentially stable children. Evidence of increasing risk with increasing traffic density was found for the total number of cancers and leukemias.

Potential sources of bias include nonresponse, differential mobility of cases and referents, unmeasured confounders, and nondifferential exposure misclassification. The precision of many of the odds ratio estimates was less than would be desirable, and random variation must be included among the possible sources of error. In order for nonresponse to have biased the odds ratios, there would have to have been a differential loss of high and low traffic density cases and referents (16). In spite of the differential response for cases and referents, such a pattern is unlikely.

The same reasoning is applicable to the concern for the differential mobility of the cases and referents. The cases were unrestricted by patterns of movement, but 
only referents who remained in their home from the time of the case's diagnosis to the time of interview were included. The relationship of residential mobility to traffic density is unknown, although one might speculate that more stable residents live in more desirable, lower traffic density homes. Referents cannot be evaluated directly for their representativeness of the exposure distribution in the study base that generated the cases, but after adjustment for a number of potential sources of selection bias, they should provide valid results.

Unmeasured confounders are always a possibility, especially when so little is known about the determinants of childhood cancer. For example, a variety of environmental and social factors is associated with living in rural versus urban settings. Any component of living in an urban area that is predictive of child hood cancer would confound the results for traffic density. Limited data on childhood leukemia do not support strong gradients by rural/urban status, with approximately a $10 \%$ increase in childhood leukemia mortality in urban areas found in one study (17) and a $10 \%$ decrease in childhood leukemia mortality reported in another (18). These data argue against substantial confounding by some unmeasured correlate of urban residence.

Finally, the inherent limitations in the marker of traffic density should be noted. Whether this is a surrogate for ambient benzene or some other component or a correlate of traffic exhaust, it contains substantial misclassification when compared with some more direct determinant of childhood cancer. Since only the street address was coded, nearby high-traffic streets were not included. The resulting misclassification is almost certain to be nondifferential with respect to the case-referent status and would thus bias the odds ratios towards the null (19).

Because of these limitations and the novelty of this observation, the study results must be interpreted very cautiously. Specifically, these data do not strongly implicate traffic-related air pollution in general (or benzene in particular) in the etiology of childhood cancer. Nonetheless, the data do suggest that an association is present between high traffic density and childhood cancer. There is no obvious methodological flaw which indicates that these results are spurious. Given the limited knowledge of risk factors for childhood cancer, further research is warranted towards identifying an environmental factor for which traffic density might serve as a marker. If the observed results are actually reflective of an underlying causative relation, then more precise measures of hypothesized etiologic agents (eg, benzene) should produce much stronger associations.

\section{Acknowledgments}

This study was part of a research program to determine the possible adverse health effects resulting from exposure to the electric and magnetic fields of overhead high-voltage transmission lines. The program was administered by the State of New York Department of Health and Health Research, Inc.

The authors thank Ms EM John and Dr RC Kleckner for their programming assistance and Dr T Morris for his critical review of the manuscript.

\section{References}

1. MacMahon B, Hutchison GB. Prenatal X-ray and childhood cancer: a review. Acta Unio Int Contra Cancrum 1964;20:1172-4.

2. Neutel CI, Buck C. Effect of smoking during pregnancy on the risk of cancer in children. J Natl Cancer Inst 1971;47:59-63.

3. Infante PF, Epstein SS, Newton WA Jr. Blood dyscrasias and childhood tumors and exposure to chlordane and heptachlor. Scand J Work Environ Health 1978; 4:137-50.

4. Greenberg BS, Schuster JL Jr. Epidemiology of cancer in children. Epidemiol Rev 1985;7:22-48.

5. Rinsky RA, Smith AB, Hornung R, et al. Benzene and leukemia: an epidemiologic risk assessment. N Engl J Med 1987;316:1044-50.

6. Checkoway H, Wilcosky T, Wolf P, Tyroler B. An evaluation of the associations of leukemia and rubber industry solvent exposures. Am J Ind Med 1984;5: 239-49.

7. Thomas TL, Waxweiler R.J. Brain tumors and occupational risk factors: a review. Scand J Work Environ Health $1986 ; 12: 1-15$.

8. Stenberg U, Alsberg T, Westerholm R. Emission of carcinogenic components with automobile exhausts. Environ Health Perspect 1983;47:53-63.

9. Holmberg B, Lundberg P. Benzene: standards, occurrence, and exposure. Am J Ind Med 1985;7:375-83.

10. Savitz D, Wachtel H, Barnes FA, John EM, Tvrdik JG. Case-control study of childhood cancer and exposure to 60 -Hertz magnetic fields. Am J Epidemiol 1988;28: $21-38$.

11. Savitz DA, Zuckerman DL. Childhood cancer in the Denver metropolitan area, 1976-1983. Cancer 1987; 59:1539-42.

12. Brookmeyer R, Liang KY, Linet $M$. Matched casecontrol designs and overmatched analyses. Am J Epidemiol 1986;124:693-701.

13. Miettinen OS. Estimability and estimation in casereferent studies. Am J Epidemiol 1976:103:226-35.

14. Mantel, Haenszel W. Statistical aspects of the analysis of data from retrospective studies of disease. J Natl Cancer Inst 1959;22:719-48.

15. Kleinbaum DG, Kupper LL, Morgenstern B. Epidemiologic research: principles and quantitative methods. Belmont, CA: Lifetime Learning Publications, 1982.

16. Greenland S, Criqui MH. Are case-control studies more vulnerable to response bias? Am J Epidemiol 1981; 114:175-7.

17. Blair A, Fraumeni JF Jr, Mason TJ. Geographic patterns of leukemia in the United States. J Chronic Dis 1980;33:251-60.

18. Selvin S, Levin LI, Merrill DW, Winkelstein W Jr. Selected epidemiologic observations of cell-specific leukemia mortality in the United States, 1969-1977. Am J Epidemiol 1983;117:140-52.

19. Copeland KT, Checkoway H, McMichael AJ, Holbrook $\mathrm{RH}$. Bias due to misclassification in the estimation of relative risk. Am J Epidemiol 1977;105:488-95.

Received for publication: 22 May 1989 